\title{
Experimental Investigations on Biological Resistance of Surface Modified Coir Geotextiles
}

\author{
S. Sumi ${ }^{1}$ (D) N. Unnikrishnan ${ }^{1} \cdot$ Lea Mathew $^{1}$
}

Received: 17 July 2016/Accepted: 8 October 2016/Published online: 19 October 2016

(C) Springer International Publishing Switzerland 2016

\begin{abstract}
Results of detailed experimental studies carried out to investigate the resistance of coir geotextiles modified using cashew nut shell liquid (CNSL) to attack of biological organisms are reported. A mixed spore suspension composed of four fungal stains, Chaetomium indicum, Curvularia lunata, Aspergillus fumigatus and Penicillium rubrum was used to study microbial susceptibility of coir geotextiles in humid warm atmosphere. Soil burial studies were carried out under controlled conditions for a period of 240 days to learn the behaviour of geotextiles in contact with specially prepared soil containing a variety of microorganisms. A field study was carried out to investigate the behaviour of coir geotextiles in subterranean termite mounds. The improved properties of modified coir geotextiles were substantiated on the basis of weight loss, moisture absorption, tensile strength and surface morphology. The results show that biological resistance of coir geotextiles was greatly improved by modification with CNSL. Tensile strength of unmodified samples reduced to $19 \%$ whereas modified geotextiles retained $76 \%$ of the initial tensile strength at the end of 240 days of soil burial. SEM images affirm that modification of coir with CNSL obtained in the present work could close the pores on fibre surface and delay biological degradation considerably.
\end{abstract}

Keywords Natural fibres · Modification - CNSL · Coir · Biodegradation - Termite resistance

S. Sumi

sumiswarrier@gmail.com

1 Department of Civil Engineering, College of Engineering Trivandrum, Trivandrum 695016, India

\section{Introduction}

Natural fibres are porous in general, and show inherent affinity to water due to the hydrophilic groups associated with the structure [1]. Association of natural fibres with moisture results in swelling of fibres leading to weakening of cell wall, thus providing easy access to microbial attack. Micro-organisms contain specific enzyme systems which can hydrolyze carbohydrate polymers in fibres to digestible units [2]. Coir being cellulosic is susceptible to degradation by micro and macro-organisms. Causative micro-organisms for degradation of lignin and cellulose in natural fibres include bacteria and fungi [3, 4]. Lignocellulosic decomposition is primarily governed by fungi while bacteria perform the role of secondary scavengers [5]. Under moist environment, fungi are reported to be highly efficient in degrading natural fibres [6]. Interaction of lignocellulosic fibres with microbes follows a degradation pathway consisting of enzymatic oxidation, reduction and hydrolysis [7].

A biologically active media at optimum moisture level is capable of quick degradation of lignocellulosic fibres. Biodegradability of natural fibres limits their use from long term applications. When geotextiles made out of natural materials such as coir are used in combination with soil, various factors such as type of soil, type of vegetation, organic content, water content, climatic conditions, rainfall and slope of terrain determine their durability [8,9]. Detailed conclusive reports on biological degradation of natural geotextiles are seldom available in literature. Balan [8] reported that degradation of coir geotextiles was at a faster rate in sand mixed with high organic content when compared to clay. It was found that coir lost $63 \%$ and $31 \%$ of initial tensile strength in sand and clay respectively after duration of one year. Coir netting, when used 
for slope stabilisation in field lost $78 \%$ of its initial tensile strength at the end of seven months [9]. $70 \%$ reduction in tensile strength was observed for coir geotextiles within a period of seven months, when used in embankment protection for watershed management [10]. A field study conducted by Joy et al. [11] reveals that depth of burial has a significant role in degradation of coir geotextiles. Durability of jute geotextile, which also is lignocellulosic, in a compost environment was found to reduce to $72 \%$ after 90 days [12]. Tensile strength of coir fibres derived from coir geotextile samples which were exposed to natural rainfall and sunlight in tropical climate of eastern Brazil were found to lose $77 \%$ of original strength after one year [13].

Higher order organisms such as termites and silverfish are also capable of attacking natural fibres [14]. Termites primarily degrade lignocellulosic fibres by mechanical chewing. Termite activity depends on various factors such as food, moisture, temperature and darkness. Subterranean termites are small ant-like social insects that live in large colonies consisting of three castes namely, workers, soldiers and reproductives. These ground termites prefer moist and dark environment and are capable of digesting cellulose [15]. Termite resistance for natural geotextiles is highly recommended as geotextiles buried in shallow depths under the ground are mostly subjected to dampness.

Biological degradation of natural fibres takes place due to the presence of free hydroxyl groups in cellulose. In moist environment, the hydrogen bonding capacity of cellulose attracts water, providing access to biological agents. Modification of lignocellulosic fibres for enhanced hydrophobicity and mechanical properties is achieved through blocking of hydroxyl groups and is universally exercised using chemical treatments. Esterification, transesterification, etherification, silane treatment and grafting have been well recognised as successful chemical modification techniques. Termite control for cellulosic materials is generally practised using chemical insecticides such as acetic anhydride [16], chlorpyrifos [17] and furfuryl alcohol [18]. These chemicals are considered to be hazardous and possibly generate toxic leachates. Plant-derived natural products for termite control have the potential to inhibit termite attack [19]. However, details of study on degradation of natural geotextiles due to termites are not reported.

Therefore, in the present work, detailed study on the effect of Cashew nut shell liquid (CNSL), a natural fungicide and termicide, on biological degradation of coir geotextiles is conducted. CNSL is a dark brown viscous liquid obtained from the soft honeycomb structure of cashew nut shell, containing cardanol and cardol as main constituents. Solubility of CNSL in most of the common solvents makes it an ideal option for surface coating of cellulosic and non cellulosic materials [20]. CNSL based surface coatings possess water repellence, antimicrobial property and resistance to termite and insect attack. CNSL polymerised with acid oxidisers such as $\mathrm{HNO}_{3}$ has been proved to be excellent for water resistant surface coatings [21]. Polymerised CNSL can modify fibre surface by forming hydrophobic, degradation-resistant coating [22]. Application of CNSL in combination with copper sulphate could extend the life of coconut thatch to 4 years [23]. CNSL based formulations have proved to impart protection against wood eating termites and fungi [24]. In a laboratory study, coir fibres coated with $20 \%$ CNSL was found to develop $95 \%$ inhibition against Aspergillus niger [25]. Experimental data on the study on degradation behaviour of unmodified and CNSL-modified coir geotextiles influenced by microbiological and termite attack under laboratory and field conditions are reported in this paper.

\section{Materials}

Coir geotextiles of type simple weave panama were procured from Charangattu coir manufacturing Co. (P) Ltd., India. Technical CNSL prepared by decarboxylation process, having viscosity $0.117 \mathrm{~Pa}$-s (at $27.8^{\circ} \mathrm{C}$ ) and specific gravity 0.96 was procured from Vijayalaxmi Cashew Company, India. Laboratory grade chemicals, copper sulphate crystals (assay $88.5 \%$, Spectrum Reagents and Chemicals Pvt. Ltd., India) and nitric acid (assay $70 \%$, NICE Chemicals, India) and locally available kerosene were used in the study. Live cultures of Curvularia lunata (NFCCI 1030), Aspergillus fumigatus (NFCCI 665) and Penicillium rubrum (NFCCI 205) were procured from National Fungal Culture Collection of India and freeze dried culture of Chaetomium indicum (MTCC 2201) from Microbial Type Culture Collection and Gene Bank, India. Fungal strains were sub cultured in bacteriological grade potato dextrose agar (HiMedia) and stored at $4{ }^{\circ} \mathrm{C}$.

\section{Methods}

\section{Surface Modification}

Coir geotextiles were cleaned in alkaline water $(\mathrm{pH} 7.5)$ and rinsed in water $(\mathrm{pH} 7 \pm 0.5)$ to ensure proper binding of coating with the geotextiles. The samples were pretreated with $1 \%$ copper sulphate solution and dried at $70{ }^{\circ} \mathrm{C}$. Based on the findings of a similar study on coir fibres [25], pretreated geotextile samples were coated with CNSL with kerosene as solvent and nitric acid ( $1 \%$ by weight of CNSL) as precursor and were cured in sunlight. Unmodified samples were taken as control. Two different concentrations of CNSL 
(20 and $40 \%$ ) were experimented to study the effect of concentration of CNSL on biological resistance properties of coir. Unmodified geotextiles, geotextiles modified with $20 \%$ CNSL and those modified with $40 \%$ CNSL (Fig. 1) were named as UM, C20 and C40 respectively.

\section{Microbial Degradation: Mixed Culture Method}

Mixed culture method as per IS 1623 [26] is recommended to evaluate the resistance of modified and unmodified jute geotextiles to the attack of micro-organisms. This method is based on subjecting jute fabrics to a mixture of selected fungal spores capable of degrading it. Owing to lignocellulosic nature of coir, the same species of fungi were adopted for this study also. A mixed spore suspension was prepared in potato dextrose media using four fungal strains, Chaetomium indicum, Curvularia lunata, Aspergillus fumigatus and Penicillium rubrum. Sterilized coir geotextile samples of size $5 \mathrm{~cm} \times 5 \mathrm{~cm}$ were wetted using sterile water and were placed on petri dishes containing potato dextrose agar. Large size samples were avoided in order to ensure proper closure of petri dish assembly and to prevent contamination. The samples were inoculated by spreading $1.5 \mathrm{ml}$ of mixed spore suspension on the middle portion. Petri dish assemblies containing modified and unmodified samples were kept in incubator for 60 days at $30 \pm 1{ }^{\circ} \mathrm{C}$. Microbial growth coverage on all incubated samples was rated as per microbial growth table mentioned in ASTM G160-12 [27]. The samples were cleaned and subjected to methanol fumes prior to drying in order to carry out SEM analysis and for determination of weight loss.

\section{Microbial Degradation: Soil Burial Method}

Degradation of coir geotextiles was studied by conducting soil burial test as per IS 1623 [26]. In this method, the geotextiles were brought in contact with a prepared- soil environment comprising of a variety micro-organisms, normally found in soil. The test soil was prepared by mixing garden soil, cow dung and sand in the ratio 2:1:1. Homogeneous mixing was ensured and moisture content of the test soil was adjusted to $27 \%$. Tests were conducted on unmodified and modified samples. A thin layer of test soil was spread on geotextile samples and the samples were rolled into cylindrical shape, with thin layer of test soil inside them as shown in Fig. 2. Each cylinder was placed separately in a container such that the all sides of the samples were in contact with the test soil. The remaining test soil was filled into each container to cover the sides and top of the container so as to form contact layers of 5-6 cm on all sides. The whole assembly was placed inside a humidity chamber maintained at a temperature of $30 \pm 1{ }^{\circ} \mathrm{C}$ and a relative humidity of $85 \pm 3 \%$. Considering the slow degradation rate of coir, a total incubation period of 240 days was taken for study although duration of only 21 days is suggested in IS 1623 [26]. A similar method suggested in ASTM G160-12 [27] recommends minimum exposure duration of 60 days. Geotextile samples were exhumed at the end of every 30 days and were washed under running water and dried until constant weights were attained. The samples were sterilized using methanol fumes prior to morphological observation, determination of wide width tensile strength and weight loss.

\section{Subterranean Termite Field Test}

Field studies were carried out to investigate the resistance of coir geotextiles to termite attack as per IS 4833 [28]. As large size samples could not be buried inside the termite mounds due to space constrains, $5 \mathrm{~cm} \times 25 \mathrm{~cm}$ samples were buried at an approximate depth of $30 \mathrm{~cm}$ and strip tensile tests were conducted. The colonies inside mounds consisted of termites of typical caste system, namely workers, soldiers and reproductives [29]. Samples were sterilized and wetted using sterile water prior to burial. The
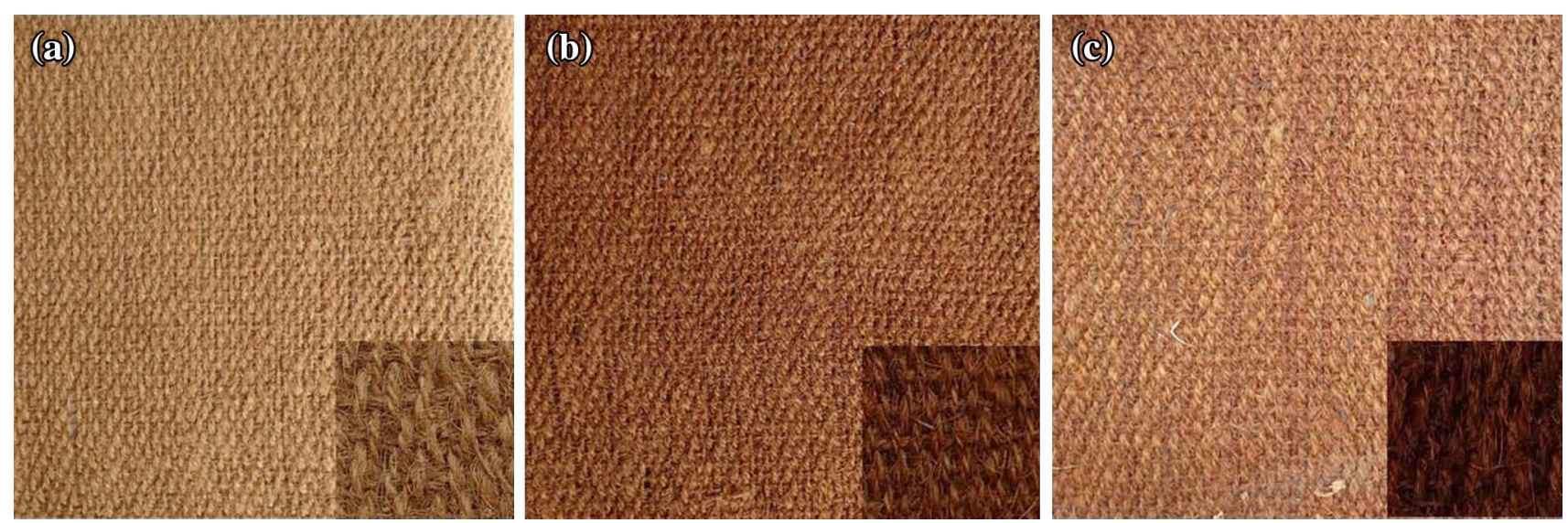

Fig. 1 Photographs of geotextiles a unmodified (UM) b modified with $20 \%$ CNSL (C20) c modified with $40 \%$ CNSL (C40) 


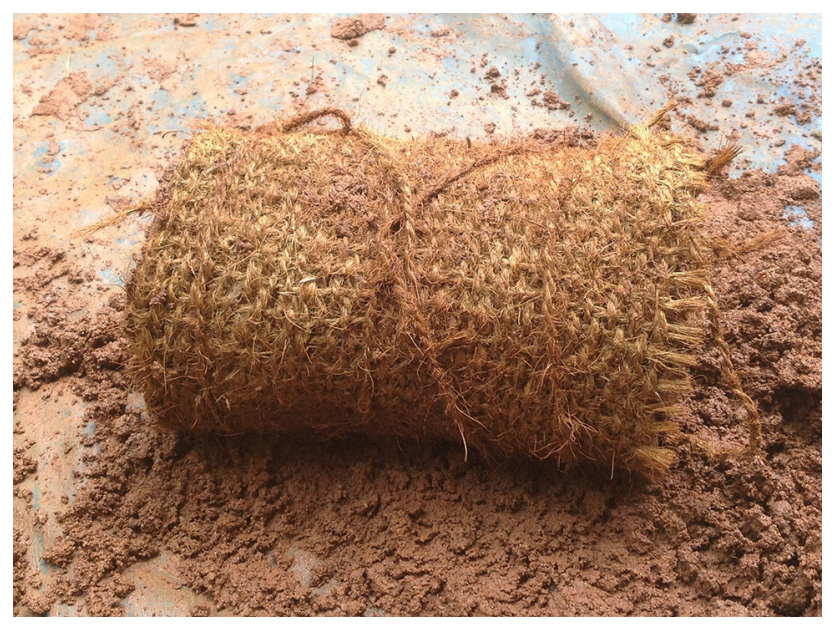

Fig. 2 Photograph of sample prepared for soil burial study

burial site was clearly demarcated and left undisturbed. Termites usually feed on cellulose that is easy to attack. Considering the slow degradation rate of coir, observations were carried out for 240 days. The study was carried out during June 2015 to December 2015. The burial site was subjected to heavy rains during the initial period, followed by occasional showers in the later stages of study. At the end of every week, the mounds were examined to ensure the survival of termites. Samples were taken out and cleaned at the end of every 30 days for visual observation and determination of tensile strength and weight loss.

\section{Testing and Characterisation}

\section{Pullout Behaviour}

Pullout test was conducted on unmodified and modified geotextiles to study the frictional resistance of modified coir. The test was conducted as per ASTMD6706 - 01 [30]. The pullout apparatus consisted of a box $610 \mathrm{~mm}$ long, $450 \mathrm{~mm}$ wide and $305 \mathrm{~mm}$ deep with a slot at mid-height to accommodate geotextile sample. Arrangements were provided for the application of normal load and pullout force. The test was conducted under three normal pressures 3,4 and $5 \mathrm{kPa}$. Pullout displacement was measured using two dial gauges for accuracy. Ratio of length of embedment to width for all samples was fixed as 2. Sand was filled in layers of $50 \mathrm{~mm}$ thickness by sand raining method. Pullout force was provided at a constant rate and corresponding displacements were recorded until the failure of sample.

\section{Weight Loss}

Weight loss is considered as a major aspect in degradation studies. For soil burial studies, perfect cleaning of coir samples exhumed from soil cannot be always ensured. Entrapment of fine soil particles and micro-organisms within the interlacing fibres even after cleaning may give rise to errors in determination of weight [31]. Hence, care was taken to exhume samples without physical damage and to ensure proper cleaning. Geotextile samples were gently cleaned in running water and dried under the sun. After $48 \mathrm{~h}$ of drying, weights were checked in an interval of every $2 \mathrm{~h}$ until constant weights were attained. Weights of geotextiles were determined before and after degradation. Weight loss was expressed as a percentage of initial dry weight.

\section{Tensile Strength}

Tensile strength of coir geotextiles was determined in Universal Testing Machine for coir geotextiles and yarn (Model: A.S.I., New Delhi, India, Capacity $50 \mathrm{kN}$ ) as per IS 13162 Part 5 [32]. Wide width tensile strength test was carried out on geotextile samples having dimensions $200 \mathrm{~mm} \times 200 \mathrm{~mm}$. Samples were tested in warp direction at a constant rate of traverse of $20 \pm 5 \mathrm{~mm} / \mathrm{min}$. Gauge length was taken as $100 \mathrm{~mm}$. Strip tensile strength test was carried out on $5 \mathrm{~mm}$ wide geotextile samples in warp direction as per IS 1969 Part 1 [33]. Gauge length was fixed as $200 \mathrm{~mm}$. Peak load was noted in both cases.

\section{Surface Morphology}

Surface morphology of coir samples before and after degradation was studied using scanning electron microscope (JOEL JSM-5600, Japan). Coir fibres were taken out from coir geotextile samples and cleaned by ultrasonication in distilled water in bath ultrasonicator (Bandelin Sonorex, Germany). Three cycles of ultrasonication of duration 3 min each were carried out to ensure proper cleaning. These fibres were dried under vacuum and 2-3 mm long portions were cut and were sputter coated with a thin layer of gold prior to examination. Observations were made at an accelerating voltage of $15 \mathrm{~V}$.

\section{Results and Discussion}

\section{Pullout Behaviour}

The studies on pullout behaviour of geotextiles proved that frictional properties of geotextiles improved significantly upon modification. Pullout resistance and pullout displacement showed a decreasing trend with increase in normal loads under three different conditions of normal pressure. Similar observations were recorded by Subaida et al. [34] while conducting pullout tests on various types 
of woven coir geotextiles. A maximum increase in pullout resistance of 43 and $45 \%$ were recorded for C20 and C40 samples respectively when compared to unmodified samples. The variation of pullout resistance with pullout force at a normal pressure of $5 \mathrm{kPa}$ is shown in Fig. 3.

\section{Microbial Degradation: Mixed Culture Method}

The fungal growth on geotextiles was evaluated periodically and growth coverage at the end of 30 days is shown in Fig. 4. Trace growth of micro-organisms was visible on unmodified samples since the 4th day of incubation itself. Fungal growth started developing at a very slow rate on coated geotextile samples after 20 days of incubation and stagnant phase was achieved in 44 days. This can be attributed to nutrient depletion within the media and reduction in moisture content in geotextile samples. Even though fungal growth on all samples started to sporulate within 45 days, observations were continued up to 60 days. Modified geotextile samples were found to impart remarkable resistance in terms of microbial attack and weight loss when compared with unmodified sample (Table 1). Higher weight loss (26\%) and heavy coverage of fungal growth on unmodified coir ascertains this result. Agar diffusion test conducted by Thilagavathi and Rajendrakumar [35] reveals that cotton fabrics coated with antimicrobial herbs exhibited large zones of inhibition when compared to unmodified fabric.

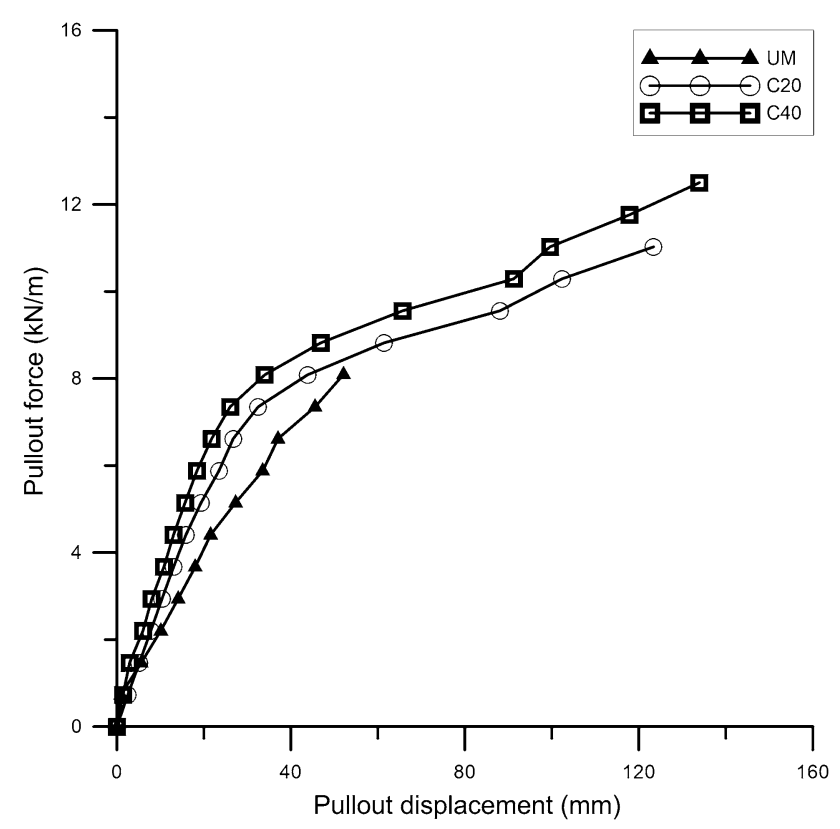

Fig. 3 Pullout resistance of geotextiles at $5 \mathrm{kPa}$

\section{Microbial Degradation: Soil Burial Method}

Wide width tensile strength of geotextiles upon modification increased by $22 \%$ for $\mathrm{C} 20$ and C40 samples. Geotextiles buried in soil were exhumed at the end of every 30 days and were cleaned and tested for tensile strength. Rate of degradation of unmodified samples was found to be fast when compared to modified samples. Tensile strength of unmodified samples reduced to $19 \%$ while modified geotextiles retained up to $76 \%$ of its initial tensile strength at the end of 240 days. Figure 5a illustrates reduction in wide width tensile strength with time. Under similar conditions of exposure, Saha et al. [12] observed that unmodified jute geotextiles were completely damaged beyond 90 days of soil burial while transesterified jute geotextiles were found to retain $37 \%$ of the initial narrow strip tensile strength of at the end of 200 days. Higher weight loss (Fig. 5b) accounts for reduced tensile strength of unmodified geotextiles. All observations from SEM images also agree with this result.

\section{Subterranean Termite Field Test}

Termite mortality remained almost unaffected in all the mounds during the period of study. Survival of termites in mounds indicates that the modification composition did not possess fast-acting toxicity. At the end of 30 days, no visible effects of termite attack were visible on all three sets of samples. At the end of 60 days, unmodified samples were found to be faintly torn while modified samples remained intact. Unmodified samples exhumed at the end of 120 days were completely degraded and weight loss could not be determined. Although modified geotextile samples were found to be undamaged in visual observations, weight loss up to $17 \%$ was observed at the end of 240 days. Corresponding reduction in strip tensile strength was found to be $21.5 \%$ for $\mathrm{C} 20$ and $20 \%$ for C40. Percentage reduction in tensile strength and weight loss of geotextiles during the test period are illustrated in Fig. 6a, $\mathrm{b}$ respectively.

Imamura and Nishimoto [16] reported that enhanced hydrophobicity of lignocellulosic materials can check dimensional increase and make it hard even in presence of moisture, making it unpalatable to termites. Modified geotextiles, being hydrophobic, might have become hard and have caused mechanical chewing difficult for termites, thereby leading termites to abandon modified geotextiles and seek alternate food sources in the field. Since geotextiles were buried in termite mounds in natural field conditions, degradation can be probably due to the combined effect of termites and soil micro-organisms. However, no fungal colony growths were visible on the surface of geotextile samples. 

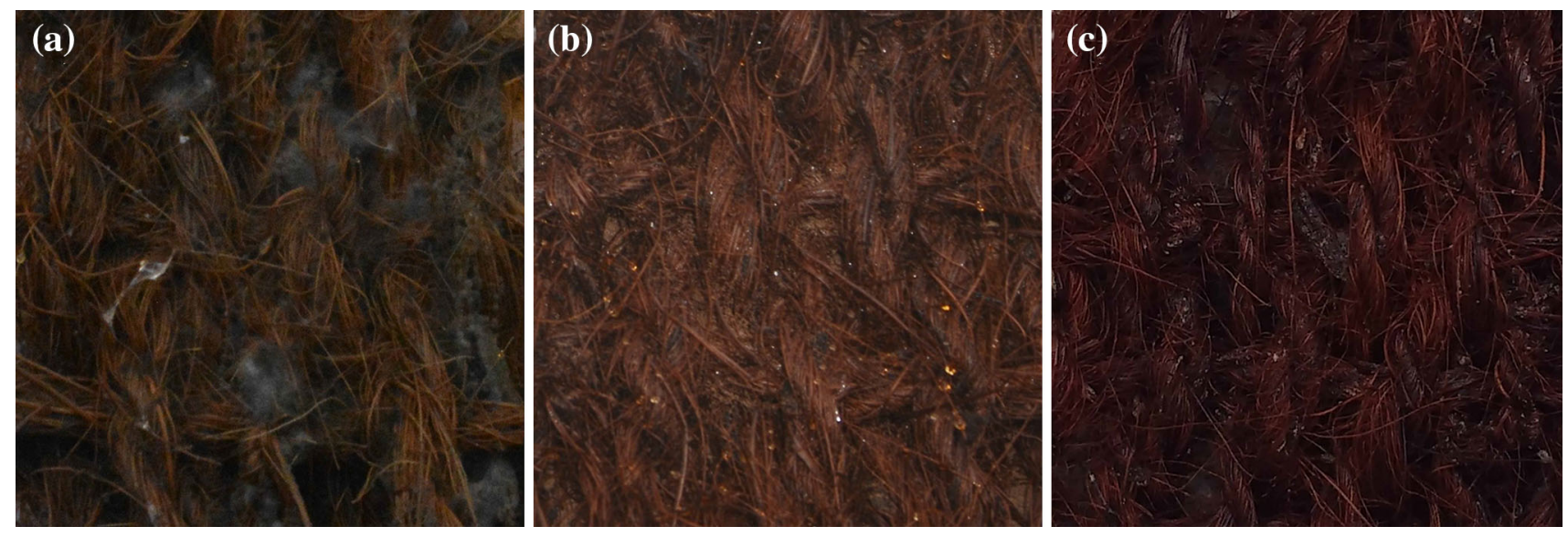

Fig. 4 Photographs of geotextiles a UM b C20 and c C40 subjected to mixed spore study after 30 days

Table 1 Observed fungal growth and weight loss in coir geotextile samples after 60 days of incubation

\begin{tabular}{|c|c|c|c|}
\hline \multirow[t]{2}{*}{ Sample } & \multicolumn{2}{|c|}{ Observed fungal growth } & \multirow{2}{*}{$\begin{array}{l}\text { Weight loss }(\%) \\
\text { after } 60 \text { days }\end{array}$} \\
\hline & 30 days & 60 days & \\
\hline UM & Moderate & Heavy & 26.22 \\
\hline $\mathrm{C} 20$ & Trace & Trace & 7.03 \\
\hline C40 & Trace & Trace & 6.54 \\
\hline
\end{tabular}

Degradation studies conducted in laboratory and field indicated that modified geotextiles were more resistant to degradation in terms of tensile strength and weight loss. It was observed that geotextiles modified with 20 and $40 \%$ CNSL concentrations resulted in similar behaviour of resistance towards microbial and termite attack and hence modification with $20 \%$ CNSL can be considered optimum. Although C20 and C40 samples exhibited similar trend of weight loss in soil burial test and subterranean termite field test, both the samples suffered relatively lesser reduction in tensile strength after termite attack. Visual observations revealed that weight loss of modified geotextiles subjected to subterranean termite field study mainly resulted from termite action on hairy projections of coir yarns whereas during soil burial, entire fabric surface was subjected to microbial attack.

\section{Surface Morphology}

Uncoated fibre exhibited vide variation in dimension with approximate diameter ranging from 85 to $103 \mu \mathrm{m}$. The (a)

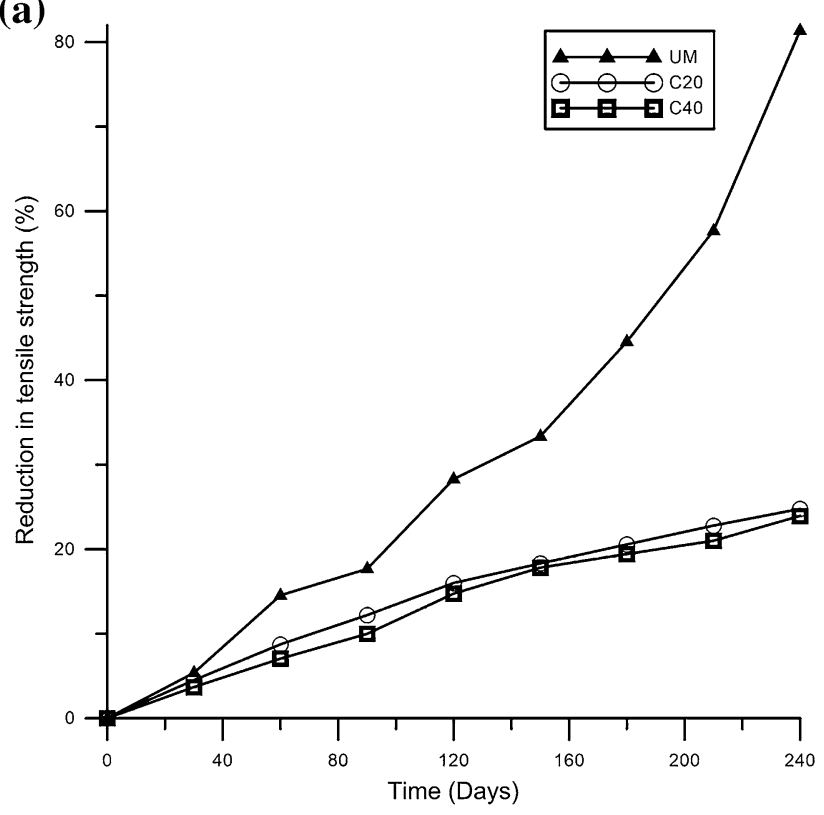

(b)

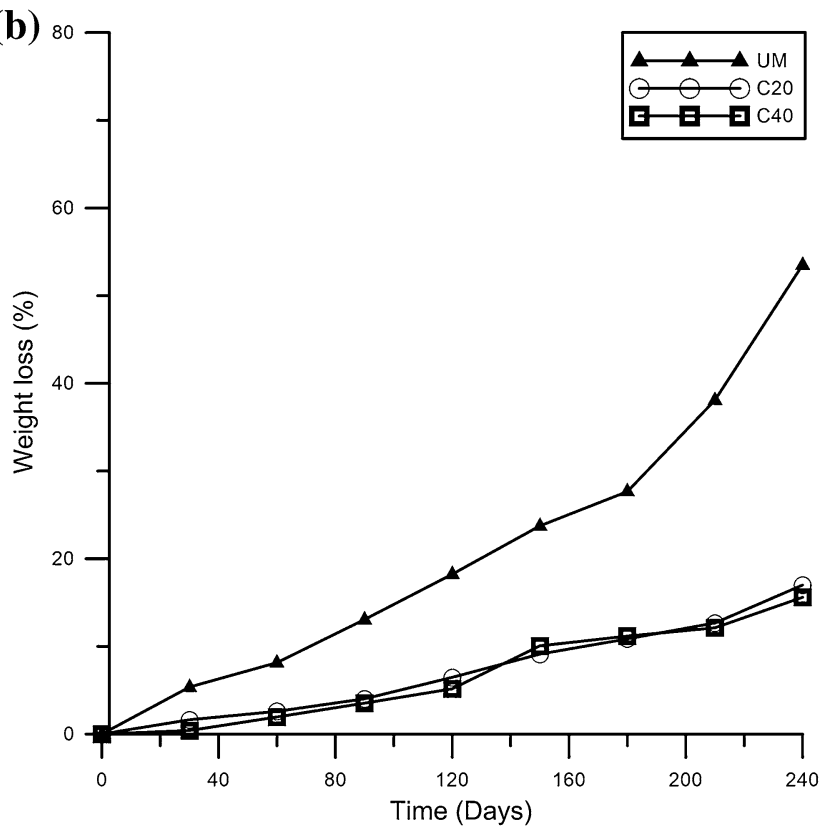

Fig. 5 a Tensile strength reduction with time $\mathbf{b}$ weight loss with time- - soil burial studies 

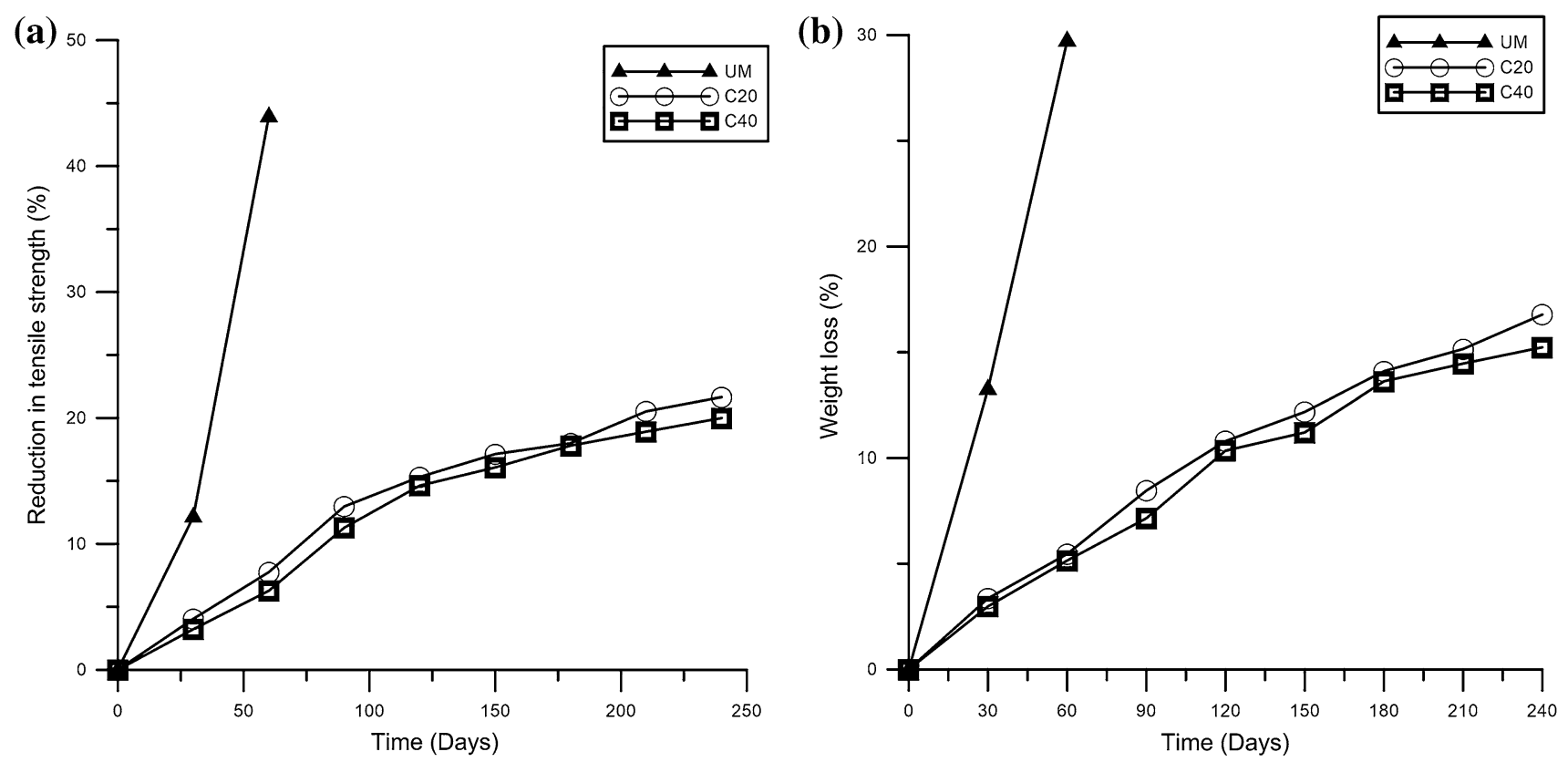

Fig. 6 a Tensile strength reduction with time $\mathbf{b}$ weight loss with time-after contact with subterranean termites

fibre surface was rough, uneven and highly porous with pore size in range $3-5 \mu \mathrm{m}$, with minute thickenings embedded at regular intervals. Similar surface morphology was reported in other works also [36-38]. SEM micrographs of unmodified and modified coir fibre samples (C40) before and after biological degradation are shown in Fig. 7a-d. The closure of surface micropores present on the unmodified coir surface was evident on the surface of modified fibre. Rahman and Khan [38] and Saha et al. [39] have also reported smoothening of lignocellulosic fibre surfaces upon surface modification.

Unmodified geotextile samples exhibited highest water uptake and lowest tensile strength with passage of time.
SEM images showed that on exposure to microbial inoculum, soil burial and termite attack, these samples exhibited rougher surfaces with pores of larger dimensions and channels when compared to modified samples. Similar results were reported by other researchers after soil burial studies. di Franco et al. [31] reported that enlarged cavities on surface of sisal fibres promoted entry of water, thus leading to microbial degradation. Balan [8] reported that diameter of coir fibre shrunk after one year of embedment in soil and fibre became brittle. In a soil digging test conducted on cotton fabrics, unmodified samples displayed structural damage in scanning electron micrographs whereas neem-treated fabrics demonstrated considerable
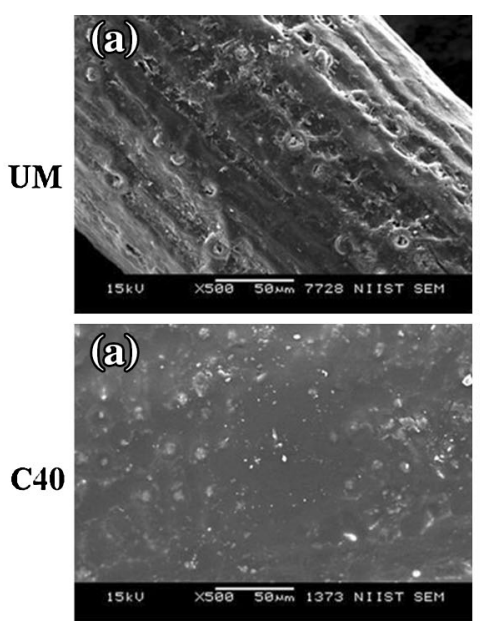
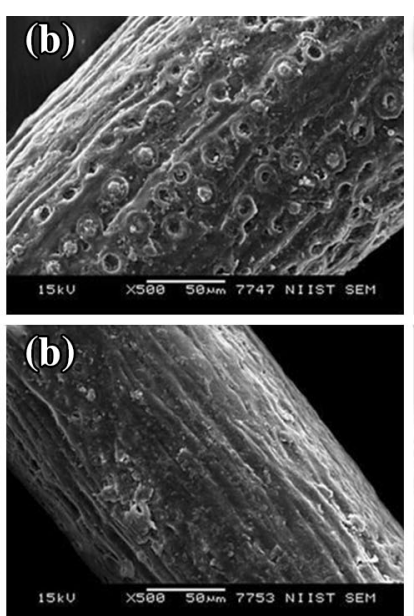
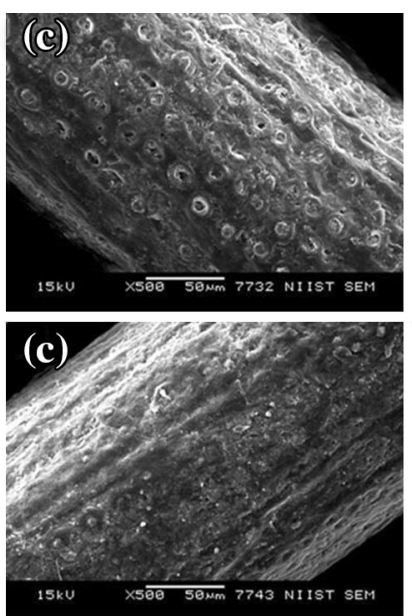
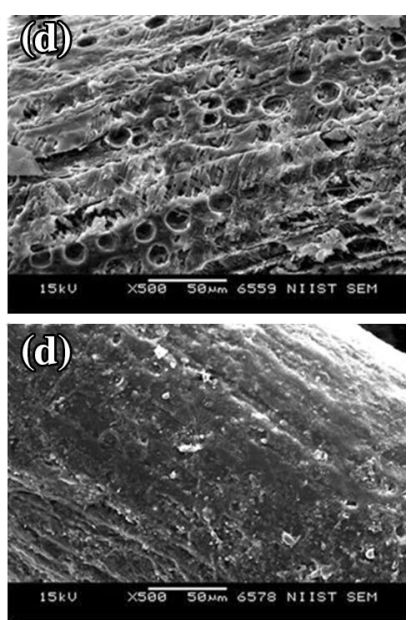

Fig. 7 SEM images of unmodified (UM) and modified (C40) geotextile fibres a before degradation $\mathbf{b}$ after 60 days of mixed spore culture study c after 90 days of degradation by subterranean termites $\mathbf{d}$ after 240 days of soil burial at magnification $\times 500$ 
resistance to degradation after 2 weeks of incubation at room temperature [35]. In the present study, surface of modified coir fibres after 240 days of soil burial was found to be reasonably uniform when compared to unmodified sample surface. This depicts that the coating composition has well adhered to the surface of coir and has remarkably sustained during the period of study. Severe degradation observed on the surface of unmodified sample can be attributed to the combined effect of humidity, temperature and mixed consortium of micro-organisms in the test soil. It is evident that the surface of coir samples exposed to soil (subterranean termite test and microbial degradation test) was subjected to greater extent of damage in comparison with the samples exposed to a fixed number of micro-organisms under laboratory conditions. Severe degradation led to weight loss of fibres, directing to reduction in tensile strength. The reduced water uptake which resulted in extended life of $\mathrm{C} 20$ and $\mathrm{C} 40$ can be attributed to the penetration of polymerised CNSL into the micropores of coir surface and the formation of a mechanically interlocked coating layer on fibre surface as depicted in SEM observations.

\section{Conclusions}

- Based on the earlier reports, the degradation of natural fibres including coir fibres is understood to be due to attack of micro-organisms and other earthy factors like humidity, temperature, and $\mathrm{pH}$ conditions and the degradation is initiated through the surface pores of the fibres. Extending life of such geotextiles is through providing a suitable antibacterial coating which can close the pores and prevent the entry of moisture into cell walls.

- Experimental studies under laboratory conditions in this work indicated that coatings of 20 and $40 \%$ modified CNSL increased the resistance of coir geotextiles against a mixed spore suspension of micro-organisms by more than $70 \%$.

- Experiments conducted over a period of 240 days where coir geotextiles were buried in an active biological media under controlled atmospheric conditions in laboratory proved that modified geotextiles retained $76 \%$ of its initial wide width tensile strength in case of surface modification compared to $<19 \%$ for the unmodified counterpart.

- More significantly, geotextiles modified with 20 and $40 \%$ CNSL retained 78 and $80 \%$ of their initial tensile strength respectively after 240 days of burial in subterranean termite mounds in field. Unmodified coir geotextiles were completely damaged at the end of 120 days.
- The role of effective coating on the fibres in geotextile is clearly evidenced through correlation with mechanical properties and changes in surface morphology. Electron microscopic observations revealed that unmodified coir samples developed rougher surfaces and deeper undulations providing easy pathways for biological degradation when compared to modified geotextiles. Surface modification showed closure of pores clearly delaying the degradation process considerably. This is further reflected with respect to the resistance towards microbial and termite attack.

- The results of present study conducted in laboratory and field conditions show that diverse conditions cause severe degradation of coir geotextiles through multiple factors emphasising the effectiveness of CNSL based modified coatings on coir geotextiles against those without modification.

Acknowledgments The authors are thankful to Kerala State Council for Science, Technology and Environment, Kerala, India for providing financial grant under ETP for the research work. The first author acknowledges Department of Technical Education, Government of Kerala, India for providing opportunity to do research under QIP scheme. Certain experimental and microscope facilities provided by CSIR-NIIST Trivandrum, India are greatly acknowledged. Authors are thankful to Dr. K. G. K. Warrier and Dr. C. Pavithran (Chief scientists (retd.), CSIR-NIIST) for the technical discussions in this work.

\section{References}

1. Rowell RM (1990) Chemical modification of lignocellulosic fibers to produce high-performance composites. In: Glass E, Swift G (ed) Agricultural and synthetic polymers: biodegradability and utilization. American Chemical Society ACS symposium series, vol 433, Washington DC, pp 242-258

2. Rowell RM (1995) A new generation of composite materials from agro-based fiber. In: Prasad PN, Mark JE, Fai TJ (eds) Polymers and other advanced materials: emerging technologies and business opportunities. Plenum Press, New York, pp 659-665

3. Basu SN, Ghose R (1962) A microscopical study on the degradation of jute fibre by micro-organisms. Text Res J 32(8):677-694. doi:10.1177/004051756203200810

4. Ghose SN, King KW (1963) The effects of physical and chemical properties of cellulosic fibers on anaerobic deterioration by pure cultures. Text Res J 33(5):392-398

5. Burgess R (2015) Synergistic degradation of lignocellulose by fungi and bacteria in boreal forest soil. MS Thesis, University of Alaska Fairbanks, Alaska

6. Chakravarty T, Bose RG, Basu SN (1962) Fungi growing on jute fabrics deteriorating under weather exposure and in storage. Appl Microbiol 10(5):441-447

7. Rowell RM (1998) Property enhanced natural fiber composite materials based on chemical modification. In: Prasad PN, Mark JE, Kandil SH, Kafafi ZH (eds) Proceedings of the fourth international conference on frontiers of polymers and advanced materials, Cairo, Egypt, January 1997, pp 717-732

8. Balan K (1995) Studies on engineering behaviour and uses of geotextile with natural fibres. Ph.D. Thesis, Indian Institute of Technology Delhi, India 
9. Lekha KR (2004) Field instrumentation and monitoring of soil erosion in coir geotextile stabilized slopes: a case study. Geotext Geomembr 22(5):399-413. doi:10.1016/j.geotexmem.2003.12. 003

10. Vishnudas S, Savenije HHG, Van der Zaag P, Anil KR, Balan K (2006) The protective and attractive covering of a vegetated embankment using coir geotextiles. Hydrol Earth Syst Sci 10(August):565-574. doi:10.5194/hess-10-565-2006

11. Joy S, Balan K, Jayasree PK (2011) Biodegradation of coir geotextile in tropical climatic conditions. In: Proceedings of the golden jubilee Indian geotechnical conference, Kochi, India, pp 604-606

12. Saha P, Roy D, Manna S, Adhikari B, Sen R, Roy S (2012) Durability of transesterified jute geotextiles. Geotext Geomembr 35(December):69-75. doi:10.1016/j.geotexmem.2012.07.003

13. Marques AR, de Oliveira Patrício PS, dos Santos FS, Monteiro ML, de Carvalho Urashima D, de Souza Rodrigues C (2014) Effects of the climatic conditions of the southeastern Brazil on degradation the fibers of coir-geotextile: evaluation of mechanical and structural properties. Geotext Geomembr 42(1):76-82. doi:10.1016/j.geotexmem.2013.07.004

14. Wilson J (2011) Fibers, yarns and fabrics: fundamental principles for the textile designer. In: Briggs-Goode A, Townsend K (eds) Textile design: principles, advances and applications. Woodhead Publishing, Cambridge, pp 3-30

15. Davenport J (1985) Environmental stress and behavioural adaptation. Croom Helm, London

16. Imamura Y, Nishimoto K (1986) Resistance of acetylated wood to attack by subterranean termites. Wood Res: Bull Wood Res Inst Kyoto Univ 72(February):37-44

17. Scheffrahn RH, Su NY, Busey P (1997) Laboratory and field evaluation of selected chemical treatment and field evaluation of selected chemical treatment for control of drywood termites (Isoptera: Kalotermitidae). J Econ Entomol 90(2):492-502. doi:10.1093/jee/90.2.492

18. Hadi YS, Westin M, Rasyid E (2005) Resistance of furfurylated wood to termite attack forest. Prod J 55(11):85-88

19. Verma M, Sharma S, Prasad R (2009) Biological alternatives for termite control: a review. Int Biodeterior Biodegrad 63(8):959-972. doi:10.1016/j.ibiod.2009.05.009

20. Lubi CM, Thachil ET (2000) Cashew nut shell liquid (CNSL): a versatile monomer for polymer synthesis. Des Monomers Polym 3(2):123-153. doi:10.1163/156855500300142834

21. Cashew Export Promotion Council (1978) Cashew nut shell liquid, extraction and uses. A survey of World Patents up to 1976. Regional Research Laboratory/Cashew Export Promotion Council of India, Hyderabad

22. Saha P, Chowdhury S, Roy D, Adhikari B, Kim JK, Thomas S (2015) A brief review on the chemical modifications of lignocellulosic fibers for durable engineering composites. Polym Bull 73(2):587-620

23. Pillai CKS, Venkataswamy MA, Satyanarayana KG, Rohatgi PK (1983) Preserving coconut leaf thatch: a simple method. Indian Coconut J 14(December):3-6
24. Remadevi OK, Nagaveni HC, Muthukrishnan R, Sharma MN (2002) Evaluation of the efficacy of cashew nut shell liquid based products (CNSL) against termites and fungi. J Timber Dev Assoc India 48(3-4):15-19

25. Sumi S, Unnikrishnan N, Lea Mathew (In-press) Surface modification of coir fibers for extended hydrophobicity and antimicrobial property for possible geotextile application. J Nat Fibers

26. IS 1623 (1992) Testing of jute fabrics for resistance to attack by micro-organisms. Bureau of Indian Standards, New Delhi

27. ASTM G160-12 (2012) Standard practice for evaluating microbial susceptibility of nonmetallic materials by laboratory soil burial. American Society for Testing and Materials, West Conshohocken

28. IS 4833- Reaffirmed: 2003 (1993) Methods for field testing of preservatives in wood. Bureau of Indian Standards, New Delhi

29. Wood TG (1988) Termites and the soil environment. Biol Fertil Soils 6(3):228-236. doi:10.1007/BF00260819

30. ASTM D6706 - 01 (2013) Standard test method for measuring geosynthetic pullout resistance in soil. American Society for Testing and Materials, West Conshohocken

31. di Franco CR, Cyras VP, Busalmen JP, Ruseckaite RA, Vàzquez A (2004) Degradation of polycaprolactone/starch blends and composites with sisal fiber. Polym Degrad Stab 86(1):95-103. doi:10.1016/j.polymdegradstab.2004.02.009

32. IS 13162-Part 5 (1992) Determination of tensile properties using a wide width strip. Bureau of Indian Standards, New Delhi

33. IS 1969 Part 1 (2009) Textiles: tensile properties of fabrics-determination of maximum force and elongation at maximum forcePart 1-Strip method. Bureau of Indian Standards, New Delhi

34. Subaida EA, Chandrakaran S, Sankar N (2008) Experimental investigations on tensile and pullout behaviour of woven coir geotextiles. Geotext Geomembr 26(October):384-392. doi:10. 1016/j.geotexmem.2008.02.005

35. Thilagavathi G, Rajendrakumar K, Rajendran R (2005) Development of ecofriendly antimicrobial textile finishes using herbs. Indian J Fibre Text Res 30(4):975-1025

36. Prasad SV, Pavithran C, Rotagi PK (1983) Alkali treatment of coir fibres for coir-polyester composites. J Mater Sci 18(5):1443-1454. doi:10.1007/BF01111964

37. Geethamma VG, Joseph R, Thomas S (1995) Short coir fiberreinforced natural rubber composites: effects of fiber length, orientation, and alkali treatment. J Appl Polym Sci 55(4):583-594. doi:10.1002/app.1995.070550405

38. Rahman MM, Khan MA (2007) Surface treatment of coir (Cocos nucifera) fibers and its influence on the fibers' physico-mechanical properties. Compos Sci Technol 67(11-12):2369-2376. doi:10.1016/j.compscitech.2007.01.009

39. Saha P, Manna S, Sen R, Roy D, Adhikari B (2012) Durability of lignocellulosic fibres treated with vegetable oil-phenolic resin. Carbohydr Polym 87(2):1628-1636. doi:10.1016/j.carbpol.2011. 09.070, 10.1007/s00289-015-1489-y 